\title{
Caminhos do rio: casas, fotografias e memória no sertão nordestino.
}

\author{
Jackeline Pinheiro Meira
}

\section{Resumo}

Este artigo faz uma análise das fachadas das casas das cidades de Juazeiro/BA e Petrolina/PE como artefatos culturais que podem se constituir "lugar de memória". Os detalhes arquitetônicos e os afrescos das fachadas remetem às lembranças de outros municípios que nasceram às margens do rio São Francisco, local de referência da pesquisa, que investiga as casas construídas nas duas cidades no final do século XIX e início do século XX, com o objetivo de desnudar possíveis prestígios da arquitetura e como vivem hoje os moradores em casas de influência portuguesa. A partir do registro fotográfico e dos relatos orais dos proprietários das casas pesquisadas, verifica-se aspectos de uma memória subterrânea presente nos testemunhos dos entrevistados e a influência das casas coloniais nos modos de vida e de representação. Utilizando a pesquisa qualitativa do tipo exploratório, relatos de história de vida nos permitiram reconstituir trajetos sobre o patrimônio arquitetônico relacionado com elementos de identidade, o valor estético atribuído à casa, o valor histórico dos afrescos, as relações sociais e culturais que marcaram a vida em comunidade dos proprietários. Já as fotografias serviram de artefatos para recorrer às memórias que surgem com as narrativas de histórias de vida, inseridas nos contextos sociais.

Palavras chave: Arquitetura. Memória. Fotografia. Sertão. Rio São Francisco.

\section{Caminos del rio: casas, fotografías y recuerdos en el sertão nordestino.}

\section{Resumen}

Este artículo hace un informe de las fachadas de las casas de las ciudades de Juazeiro/BA y Petrolina/PE como artefactos culturales que pueden se constituir "lugar de memorias". Los detalles arquitectónicos y afrescos de las fachadas remeten a recuerdos de otros municipios que nascieran en las márgenes del rio São Francisco, local de referencia de la pesquisa. La pesquisa investiga las casas construidas en las dos ciudades al final del siglo XIX y principio del siglo XX, con objetivo de desnudar las posibles prestigios de la arquitectura y como viven hoy los moradores en casas de influencia portuguesa. A partir del registro fotográfico y de los relatos orales con los propietarios de las casas pesquisadas, verificase aspectos de una memoria subterránea presente en los testimonios de los entrevistados y la influencia de casas coloniales en el modo de vida y de representación. Utilizando la pesquisa cualitativa de tipo exploratorio, relatos de historia de vida nos permitieran reconstituir trayectos sobre el patrimonio arquitectónico relacionado con elementos de identidad, el valor estético atribuido a la casa, el valor histórico de los afrescos, las relaciones sociales y culturales que marcan la vida en comunidad de los propietarios. Ya las fotografías sirvieran de artefactos para recorrer 
a las memorias que surgen con las narrativas de historias de vida, inseridas en los contextos sociales.

Palabras llave: Arquitectura. Memoria. Fotografía. Sertão. Rio São Francisco

Paths of the river: homes, photographs and memories in the sertão nordestino.

\section{Resume}

This article makes a note about the facade of the houses from Juazeiro/BA and Petrolina/PE as cultural artefacts that can constitute a "place of memory". The architectural details and the afrescos from the facades refer to memories from ther municipalities that were born at the São Francisco river banks, referential place of the research. The research investigates the houses built in both towns at the end of the XIX century and beginning of the XX century, with the goal to show the possible prestige of the architecture and how the residents live today in Portuguese influenced houses. From the photographical record and oral reports with the owners of the researched homes, there are aspects of an underground memory present in the testimony of the interviewed and the influence of the colonial houses in the way of life and representation. Using a qualitative research of exploratory type, reports from life history allowed us to reconstruct paths about the architectonical heritage related with identity elements, the esthetical value attributed to the house, the historical value of the afrescos, the social and cultural relations that marked the community life of the owners. The photographs served as artefacts to resort to the memories that arise with the narratives of the life histories, inserted in the social context.

Key words: Architecture. Memory. Photograph. Sertão. São Francisco river. 


\section{Introdução}

Ao longo dos séculos XIX e XX, a região do sub-médio do São Francisco se caracterizou por uma arquitetura pós-colonial com traços do ecletismo, testemunhas das influências culturais e do forte desenvolvimento comercial como entreposto e local de passagem de viajantes.

A influência dessa arquitetura pós-colonial pode ser verificada a partir do patrimônio arquitetônico e dos afrescos e desenhos das fachadas das casas, assim como dos relatos dos moradores. Maria Isabel Figueiredo, neta do barão Enéas Muniz, dono de um dos primeiros sobrados da cidade de Juazeiro, que ainda resiste ao tempo e à modernidade, narra com orgulho a história do sobrado da família, situado no centro de Juazeiro-Bahia.

O sobrado tem uma beleza grandiosa, alusão ao poder existente entre o final do século XIX e o início do século XX. No local, eram realizados saraus e festas de reis, produzidos pelo próprio barão e os familiares, que atribuíam à festa a simbologia de mais um ano de fartura na residência. Festa, ainda hoje lembrada no dia de reis pelas netas do barão Enéas, as senhoras Grassú e Maria Isabel.

Segundo Bebela, como é carinhosamente chamada Maria Isabel, as fachadas naquele tempo indicavam, entre outros, o grau de poder ou de dinheiro que a família proprietária possuía. A depender da classe social, as casas eram construídas com fachadas ornamentadas com diversos desenhos nas platibandas ${ }^{1}$ e ao redor das janelas, moldadas com a cal, em um composto com óleo de peixe ou baleia que vinha da capital para dar a forma do desenho e a liga.

Elemento presente na construção das casas do século XX, a platibanda se tornou obrigatório a partir do regimento do Código de Postura em alguns estados, inclusive na Bahia (REIS FILHO, 1978). Tinha a finalidade técnica de conduzir o escoamento da água da chuva para a parte lateral da casa, evitando que caísse diretamente na rua, uma vez que a maioria das casas

\footnotetext{
${ }^{1}$ Faixa emoldurada instalada na parte superior das casas ou edifícios, normalmente com a função de esconder o telhado.
} 
ficava posicionada rente ao passeio. Dessa maneira, evitava-se que as pessoas que faziam uso das calçadas fossem molhadas. A platibanda emoldurava a parte superior das casas e representava símbolo da classe social a que pertencia uma família. Muitas vezes, camuflava o tamanho real de uma casa simples.

Ao longo dos anos, as fachadas foram sendo modificadas e muitas delas não têm registro visual, seja por meio da documentação como fotografias, vídeos ou desenhos arquitetônicos que revelassem a originalidade das casas.

Diante da importância dessas fachadas, esses artefatos materiais podem se constituir como "lugares de memória", visto que são lugares simbólicos que garantem ao mesmo tempo a cristalização da lembrança e a sua transmissão (NORA, 1993, p.7-22). Nessa perspectiva, desenvolvi projeto de pesquisa ${ }^{2}$ para documentar as casas por meio de imagens fotográficas e evidenciar a memória de um tempo.

Neste artigo, buscaremos analisar a imagem das fachadas das casas construídas no final do século XIX e inicio do século XX em Juazeiro, na Bahia, e Petrolina, em Pernambuco, como parte da memória das cidades e artefatos culturais que podem ser constituir como "lugar de memória". Além de ser um trabalho de valorização do patrimônio arquitetônico e de construção de uma memória da cidade, havia encontrado um meio de estar mais próxima dessa experiência, um conjunto de reminiscências da minha infância, na cidade de Xique-Xique, atrelado a "causos" cheios de nostalgia.

Assim, analisei as fachadas das casas e realizei registros fotográficos das residências. Para tanto, recorri aos métodos etnográficos por meio da coleta de imagens fotográficas das casas, uma vez que não há documentação visual sobre a maioria das cidades ao longo do rio nos acervos das Bibliotecas Públicas Municipais.

Souza (2002) atenta para o uso da fotografia como documento que registra uma imagem no tempo, uma vez que essas cidades - a começar por

\footnotetext{
${ }^{2}$ A dissertação Cal, Barro \& Luz: memória e identidade cultural de moradores das casas com desenhos nas fachadas nas cidades de Juazeiro/BA e Petrolina/PE foi apresentada ao Programa de Pós-Graduação em Desenho, Cultura e Interatividade, na Linha de Pesquisa, Desenho e Cultura, da Universidade Estadual de Feira de Santana/BA, sob orientação da professora Dr $^{\mathrm{a}}$ Marise de Santana. Cal, Barro \& Luz: memória fotográfica do patrimônio arquitetônico de Juazeiro/BA e Petrolina/PE. TCC apresentado no curso de Jornalismo em Multimeios, na Universidade do Estado da Bahia, sob a orientação da professora Dr $^{\mathrm{a}}$ Andrea Cristiana Santos.
} 
onde residi, Juazeiro e Petrolina -, sofrem uma rápida transformação no panorama urbano, acentuadamente desde a chegada dos projetos de irrigação no Sub-Médio do São Francisco, a partir da década de 1970.

Dessa forma, as fachadas poderão fazer emergir ainda lembranças acerca de pessoas que habitavam a casa, uma vez que algumas podem trazer até insígnias do proprietário, o ano de construção ou formas e desenhos que visualizamos, os costumes e a cultura dos moradores dessas casas. Ao contemplar as imagens das fachadas, muitas vezes ocorre um processo de reconhecimento dos moradores com as suas residências, podendo vir a constituir um laço afetivo, assim como um sentimento de pertencimento e de comunidade.

São também essas fachadas que podem evidenciar as heranças das etnias que, ao longo dos anos, moraram nas cidades e misturaram as suas raízes na cultura predominante dos dois estados, ora pernambucano, ora baiano, berço de um conjunto ainda em construção, herdeiro de muitos povos, portugueses, africanos, holandeses, índios nativos, que ainda hoje contribuem para a arquitetura de uma cultura que a cada dia sofre mudanças.

Para este artigo foram selecionadas oito casas, em que os proprietários/ocupantes estavam disponíveis para facultar o registro dos interiores e para a realização de entrevista. As fotografias documentam casas que atendem a critérios de relevância como: valor histórico; qualidade arquitetônica relacionada a estilos; fruição estética ao despertar sensibilidade pela beleza; valor sentimental, entre outros.

A proposta de pesquisar as casas através da fotografia aliado aos usos e as representações que os proprietários/moradores fazem das casas de influência colonial nos remetem necessariamente para um trabalho de contextualização histórica do desenvolvimento destas regiões.

Assim, na primeira iniciativa de documentar a história dos "sertões de dentro", como denominava a região em obra de 1907, Capistrano de Abreu (1988) buscou construir uma identidade própria do interior do Brasil, em especial da região nordeste, apresentando extensa argumentação a respeito da vida, dos costumes e dos valores atribuídos por ele aos habitantes locais, fundada na ideia de uma "civilização do couro", proveniente do 
desbravamento da região pelos bandeirantes e sua posterior ocupação por criatórios de gado (DINIZ, 2013, p.4).

Atualmente, é significativo o número de escritores sertanejos que retratam a memória das suas cidades, seu povo, seus costumes e a glória do passado. Jorge de Souza Duarte (1985) e Maria Creuza de Sá y Brito (1995) trazem uma leitura sucinta sobre personagens que fizeram a história das cidades ribeirinhas, das construções inseridas nesse contexto e sua importância.

Em Juazeiro e Petrolina, assim como em outras cidades ao longo do rio São Francisco, muito da história foi contada através destes escritores, cujas informações delimitam a trajetória das cidades, e dos que lá moram e moraram com as peculiaridades de cada família, uma vez que, cada época, é narrada conforme fatos e fotografias reveladas pelos historiadores e memorialistas com acervos particulares, como o arquivo de Maria Franca Pires $^{3}$, professora juazeirense que reuniu extenso material sobre a história da educação da cidade, selecionando imagens e fotografias, atualmente sobre a guarda da professora Odomaria Bandeira, da Universidade do Estado da Bahia.

Através dos relatos orais dos moradores procurou-se verificar a relação dos mesmos com as casas e se evidenciou aspectos dos motivos que os levavam a escolher os desenhos, uma vez que as cidades de Juazeiro e Petrolina estavam razoavelmente afastadas dos grandes centros. Construídas entre o final do século XIX e início da década de 1930, as construções revelam a herança histórica herdada dos personagens que a habitaram e habitam como é o caso das que fazem parte desta temática.

Delimitamos o tipo de pesquisa qualitativa, caracterizada por Richardson (2012), como uma tentativa de uma compreensão detalhada dos significados e características situacionais apresentadas pelos entrevistados, em lugar da produção de medidas quantitativas de características ou comportamentos.

\footnotetext{
${ }^{3}$ O Arquivo da Prof ${ }^{a}$ Maria Franca Pires: memória e história cultural em pesquisa na região de Juazeiro/BA está localizado na Universidade do Estado da Bahia(UNEB), no Departamento de Ciências Humanas (DCH III). A pesquisa compõe com o levantamento do acervo do arquivo pessoal de uma professora; o inventário de fontes a partir dos materiais levantados do acervo; o estudo da memória ali representada e a reconstituição da história cultural regional.
} 
Acrescentamos ainda a natureza de pesquisa qualitativa do tipo exploratório que consiste em "uma avaliação de uma situação concreta desconhecida, em um dado local, alguém ou um grupo" (LAKATOS\&MARCONI, 1992, p.110).

Investimos ainda na leitura de estudos sobre fotografia e cultura material, técnicas de entrevistas e de registro fotográfico das casas. As entrevistas foram usadas com a finalidade de analisar as percepções dos moradores em relação aos usos das casas de influência colonial, o que pode variar segundo o contexto que estão sendo inseridas. Richardson (2012) compreende a entrevista como uma técnica importante que permite o desenvolvimento de uma estreita relação entre as pessoas. É uma comunicação bilateral.

As fontes orais, resultantes do trabalho de entrevistas no campo de estudo, se associaram ao registro fotográfico para compor um conjunto de dados que são trabalhados à luz da problemática da memória, do patrimônio e da etnicidade nos processos de ocupação e elaboração das identidades locais.

A fotografia se constitui como instrumento metodológico primordial. Ela é usada como duplo recurso metodológico. Por um lado, o registro fotográfico permite constituir um banco de imagens. Por outro lado, as fotografias foram usadas para, através da técnica de foto-elicitação ${ }^{4}$, conduzir as entrevistas realizadas.

Segundo Milton Guran, (1992, p.15), a fotografia é uma extensão da nossa capacidade de olhar e se constitui em uma técnica de representação da realidade que, pelo seu rigor e particularismo, se expressa através de uma linguagem própria e inconfundível.

Numa fotografia há um universo de sentidos, a imagem tem várias camadas de sentidos. Há os objetos, que podem ser literalmente descritos. Mas também há os processos sociais que fazem aparecer os objetos que se veem na fotografia. Existe também o valor que as pessoas atribuem relacionados aos processos sociais e aos objetos.

\section{Do patrimônio à memória}

\footnotetext{
${ }^{4}$ Técnica que usa a fotografia como suporte da entrevista, uma alternativa às entrevistas clássicas.
} 
Com o crescimento das cidades devido ao comércio, casas e casarões começam a surgir no início do século XX nas cidades de Juazeiro e Petrolina. O estilo neoclássico com características trazidas da Europa para o Brasil fazia jus as fachadas encontradas no interior, muitas vezes cópias de fachadas encontradas nas capitais.

As casas eram construídas em adobe a partir de uma mistura de barro e folhas, como tijolos artesanais. Segundo Nei Barbosa, 47 anos, mestre de obras e morador da Rua Conselheiro João Alfredo, número 2007, em Petrolina, a reforma dessas casas precisa de uma preparação prévia, como o isolamento do barro com telhas, para depois colocar a cal e, por último, a pintura, e que dificilmente acertam os detalhes.

Nei fala com emoção sobre a dificuldade de manter a casa com a fachada original, já que a cidade não dispõe de profissionais que saibam trabalhar nas platibandas sem prejudicar os desenhos. Ele alerta sobre o rompimento dos laços familiares de alguns moradores para com as fachadas das casas, devido a essa dificuldade e também a modelos mais modernos de fachadas com garagens, varandas e jardins que fazem parte hoje da nova morada.

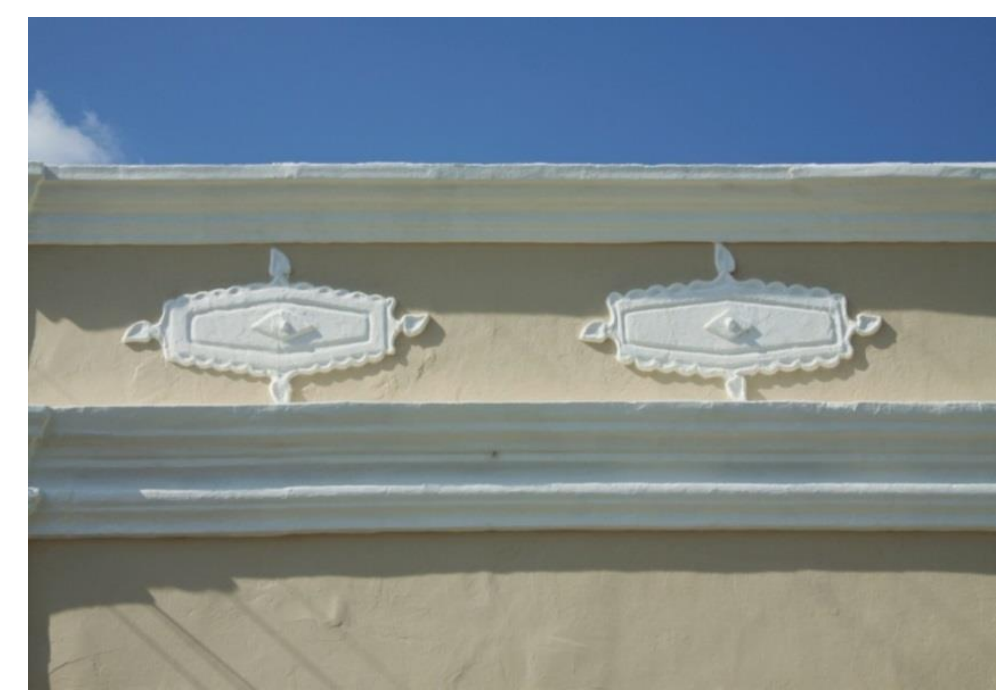

Figura 1: Platibanda na casa de Idelzuite e Nei Barreto Fonte: Acervo Pessoal Jackelina Kern

Dona Celita, de 78 anos, proprietária de uma residência na cidade, que ainda preserva uma platibanda, confessa que a reforma mais significativa que fez na casa foi construir uma varanda: 
Sempre foi assim desde a época da minha mãe e não quis mexer, deixei como ela gostava. Agora a varanda é por que não tinha jeito, foi preciso, sempre ficamos sentados na porta, agora podemos ficar na varanda que é tão fresco quanto a porta. Tá tendo muita coisa aqui na redondeza, muita violência e já não podemos sentar na porta. Mas é bonito também essa fachada aí em forma de risco.

Muitas vezes, existe a necessidade de mudanças nas residências, seja por situação de crescimento familiar, estrutura das casas ou mesmo por falta de profissionais capazes de trabalhar a cal e o barro, situação essa mais comum entre os entrevistados.

Stellita Santana conta que, devido à falta de profissionais, todos os desenhos e pinturas que havia dentro de casa, assim como na sala de visitas, foram se apagando com o tempo por não encontrarem um profissional que recuperasse a pintura nas paredes.

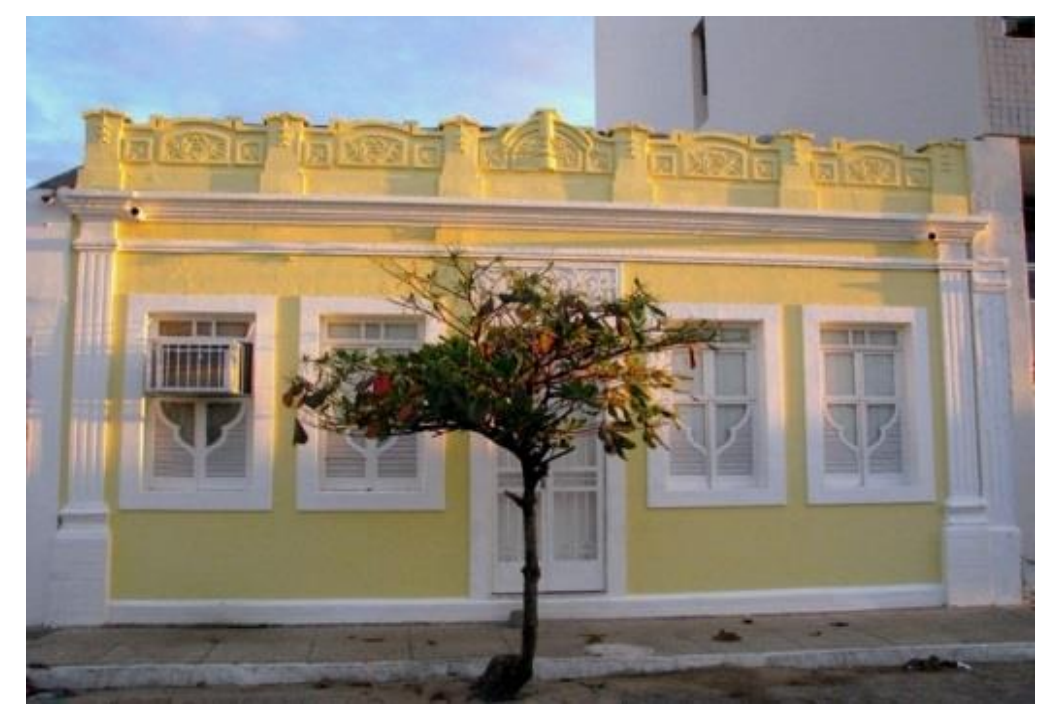

Figura 2: Casa de Stellita Santana e Déa Raquel, Petrolina/PE

Fonte: Acervo Pessoal Jackelina Kern

Se atualmente não existem profissionais que trabalhem com os desenhos de platibandas, as pinturas no teto e nas paredes, quem eram, afinal, esses artífices que tão bem trabalhavam a cal?

Filho (1978, p. 54) relata que:

Conservando-se ainda as técnicas de construção e uso dos edifícios, largamente apoiados na abundancia de mão-de-obra mais grosseira e, em pequena parte, artesanal, era natural que se repetissem os esquemas de fins de século XIX, com soluções mais ou menos rústicas, com edifícios sobre o alinhamento da via pública, a revelar, em quase todos os detalhes, os 
compromissos de um passado ainda recente com o de trabalho escravo e com os esquemas rígidos dos tempos coloniais.

Nos registros encontrados na Casa dos Artífices, fundada no ano de 1928, com o nome Sociedade Beneficente dos Artistas juazeirenses, criada pelos trabalhadores na arte da construção como pedreiros, marceneiros, carpinteiros e pintores, cuja organização marcou a vida administrativa e urbanística da cidade, não encontramos documentos no local pela degradação que sofreu ao longo dos anos.

Hoje sob os cuidados da senhora Flor de Maria Bandeira e alguns sócios, que colaboram com uma quantia simbólica, a fachada continua preservada assim como o seu maior bem: a porta desenhada pelos artífices da época, como Saul Rosa e Cecílio Matos.

$\mathrm{Na}$ cidade de Juazeiro, a partir das entrevistas com moradores, notamos que desagrada o processo de destruição do patrimônio e das fachadas. O visual externo das casas que enobrece as duas cidades caminha com o desenvolvimento, atraindo novos moradores que aprovam a manutenção do centro histórico das cidades. Já foram realizadas muitas manifestações em Juazeiro pela falta de preservação das casas que não são regulamentadas como patrimônio, embora já tenha havido várias tentativas para que esse acontecimento viesse a ser uma realidade.

Em Petrolina, existe hoje a rua que foi designada de Petrolina Antiga por causa da existência dos casarões que ainda resistem. No passado, foram depósitos de algodão da família Coelho, família de comerciantes e políticos da cidade como Nilo Coelho, que foi Governador e Senador do Estado de Pernambuco. 


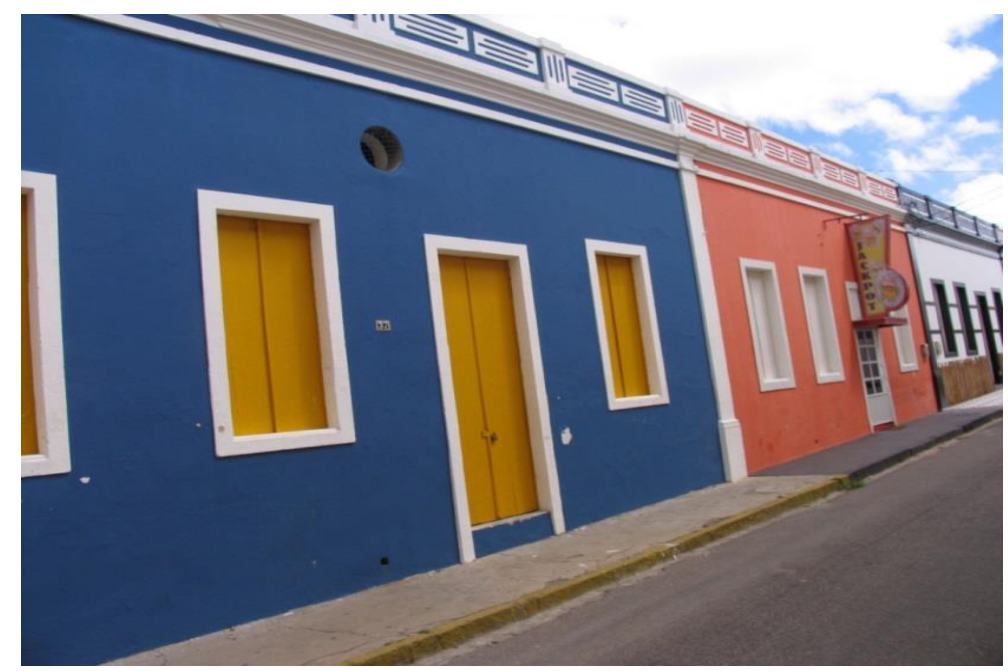

Figura 3: Antigos Armazéns de Algodão da Família Coelho em Petrolina Fonte: Arquivo Pessoal Jackelina Kern

Casas construídas no início do século XX, com suas belas platibandas decoradas, tornaram-se referência principalmente no quesito gastronômico da cidade, desde o ano de 2003 até os dias atuais. São desenhos geométricos de grande beleza que imediatamente instigam os nossos olhares para o alto, uma vez que, no resto da fachada compreendemos não haver além dos janelões, algo capaz de chamar tanta atenção como as platibandas e as cores.

Com desenhos escalonados, comum no sertão do Brasil, os armazéns da Petrolina antiga se destacam pelo estilo colonial brasileiro de uma porta e duas janelas, com as bicas não mais na parte superior da fachada. Assim como quando as portuguesas que chegavam ao Brasil não podiam molhar ou sujar as suas vestes com a água que caia do telhado, a região do vale utiliza do exemplo e começa a dar lugar às platibandas.

O status social também começa aqui a ser definido com a arquitetura e outros elementos utilizados como janelas ornamentadas, estátuas, rigor métrico, frontões com suas linhas curvas e vidros coloridos, que normalmente vinham da Europa. Reis Filho (1978, p. 142) alerta que:

É interessante observar que, mesmo consideradas todas as adaptações sofridas no Brasil pelo Neoclassicismo ou por outros movimentos artísticos, verifica-se uma tendência, justamente nas camadas consumidoras dessa arte, para afirmar a sua desnacionalização e o seu caráter exclusivo de importação, bem como a ausência nela de originalidade e de valor artístico próprio. Essa posição correspondente a uma tentativa de provar a perfeição desses copismos, e portanto o caráter europeu dessa arquitetura e de seus proprietários, mas significa ao mesmo 
tempo uma negação da vida local e, em última análise, da história local e de si mesma.

Seguindo a discussão levantada por Reis Filho, as platibandas presentes nas casas de proprietários mais abastados dispunham de objetos como louças do Porto, como compoteiras, vasos e bichos. Já os desenhos dispostos nas casas de pessoas com menor poder aquisitivo, os afrescos são mais simples e fazem alusão aos trilhos de trem, estradas e rodas.

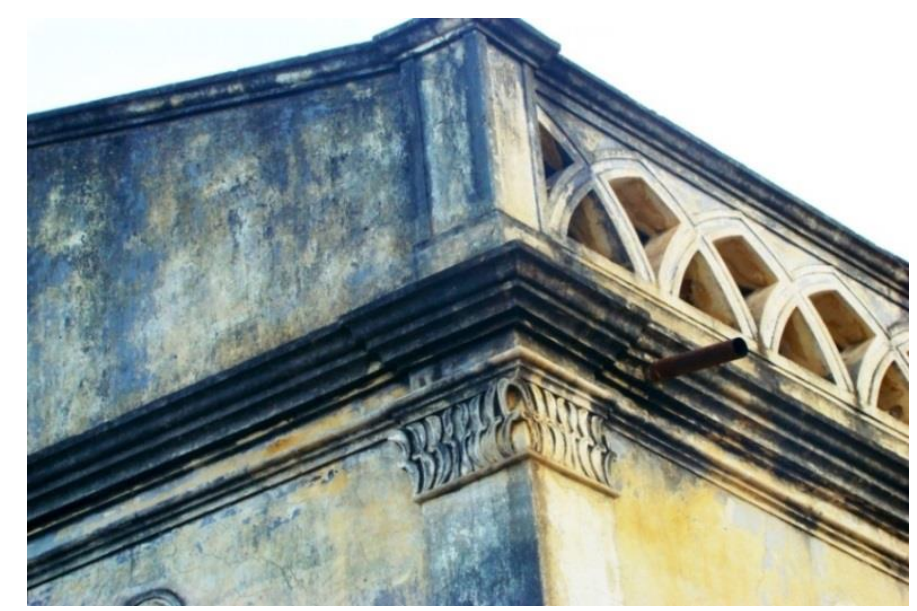

Figura X. Platibanda vazada em Juazeiro/BA Casa do Barão Enéas.

Fonte: Arquivo pessoal Jackelina Kern

Ainda assim, por meio da sabedoria popular, a comunidade manteve suas tradições, a visibilidade que ora adentra o pensamento de um povo, é colocada como um marco de conquistas pela imprensa, pelos moradores juazeirenses e petrolinenses através da valorização do que somos enquanto cidadãos culturais. Os eventos promovidos por pessoas e entidades, ainda que sem fins lucrativos, exploram e divulgam o saber local e transformam o pensar - principalmente dos menos favorecidos - em relação ao que denominamos cultura.

Ruskin (2008, p.54), desenhista e crítico de arte nos diz que:

É como centralizadora e protetora dessa influência sagrada, que a Arquitetura deve ser considerada por nós com a maior seriedade. Nós podemos viver sem ela, e orar sem ela, mas não podemos rememorar sem ela. Como é fria toda a história, como é sem vida toda fantasia, comparada àquilo que a nação viva escreve, e o mármore incorruptível ostenta! - quantas páginas de registro duvidosos não poderíamos nós dispensar, em troca de algumas pedras empilhadas umas sobre as outras! A ambição dos construtores da velha Babel volta-se para esse mundo: há apenas dois fortes vencedores do esquecimento dos homens, 
Poesia e Arquitetura; e a última de alguma forma inclui a primeira, e é mais poderosa na sua realidade: é bom ter ao alcance não apenas o que os homens pensaram e sentiram, mas o que suas mãos manusearam, e sua força forjou, e seus olhos contemplaram, durante todos os dias de suas vidas.

Ruskin (2008) analisa que a arquitetura é a arte que dispõe e adorna de tal forma as construções erguidas pelo homem, para qualquer uso, que vê-las pode contribuir para sua saúde mental, poder e prazer. Fazer as pessoas entenderem que nas fachadas pode estar contida parte da memória de uma cidade, através da imagem visual e da história de cada casa, pode favorecer a interação da história individual que passará a ser coletivo em um futuro próximo.

Pensei como essas pessoas poderiam identificar que arquitetura é também memória, é história, que faz parte não só da vida de quem herdou o patrimônio, a construção arquitetônica, mas que, e primordialmente, faz parte de uma memória coletiva e individual.

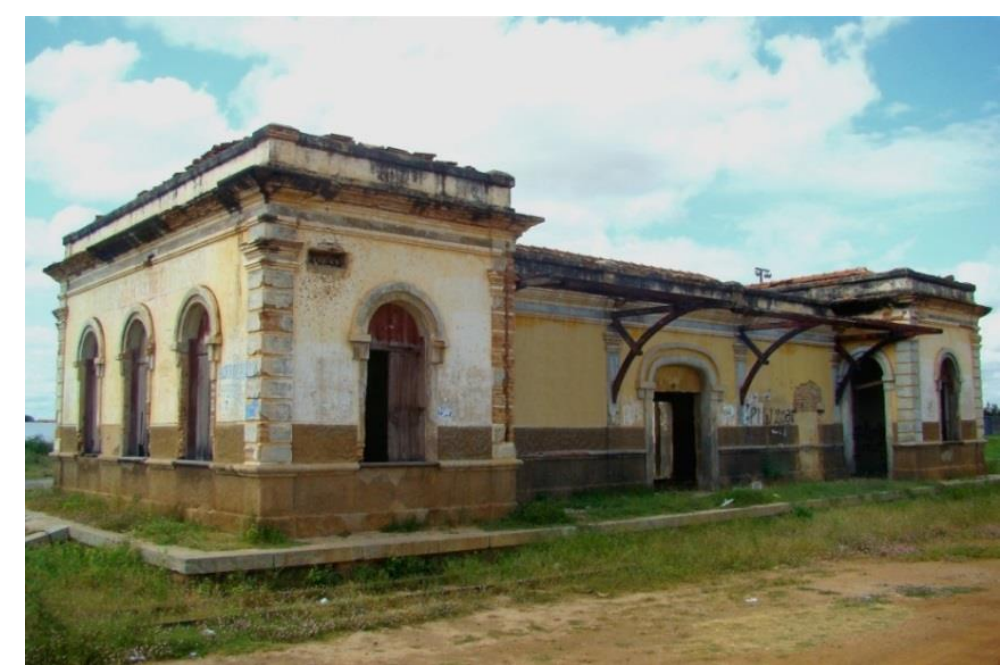

Figura 5: Antiga Estação de Juazeiro/BA

Fonte: Acervo pessoal Jackelina Kern

Halbwachs (2008, p.75) enfatiza que um acontecimento só toma lugar na série dos fatos históricos algum tempo depois de ocorrido. Portanto, somente bem mais tarde é que podemos associar as diversas fases de nossa vida aos acontecimentos nacionais. Até então as nossas memórias ficam ali guardadas tentando encontrar um meio de evolução de fatos acontecidos ou silenciadas para sempre. 
Como diz Pollack (1989, p.6) distinguir entre conjunturas favoráveis ou desfavoráveis às memórias marginalizadas é reconhecer a que ponto o presente colore o passado. Conforme as circunstâncias ocorrem à emergência de certas lembranças, a ênfase é dada a um ou outro aspecto.

Nesse sentido, o reconhecimento na memória coletiva depende, por vezes, do que reconhecemos e exteriorizamos da nossa memória individual. Uma busca daquilo que queremos dentro de nós para que possa firmar o pensamento e a cultura ao nosso redor, em torno das pessoas com quem convivemos e nos locais por onde passamos e nos enxergamos parte dessa cultura.

Dessa maneira, a memória ativada em torno de nós mesmos é expandida aos costumes daquilo que nos rodeiam e de fatos que nos marcaram no plano coletivo. Deste modo, compreendo que a preservação do patrimônio, assim como a memória, faz parte de uma discussão que ultrapassa o sentido individual. É preciso que a nossa memória individual se beneficie da dos outros para que a lembrança que os outros nos trazem possa ser objeto de uma reconstrução sobre uma base comum. É como se estivéssemos diante de muitos testemunhos.

Podemos reconstruir um conjunto de lembranças de maneira a reconhecêlo porque eles concordam no essencial, apesar de certas divergências (HALBWACHS, 2008). O reconhecimento de certas recordações, por vezes, é a base das discussões entre pessoas que vivenciaram as mesmas emoções e retrocederam nelas.

Pesquisar a história da coletividade sobre o patrimônio arquitetônico reforça o desejo de que, no futuro, a sociedade presente conheça o passado, ainda que pensemos que nada dura para sempre, inclusive nós. Mas ao pensar que partimos e que a nossa história ficou construída através dos nossos pertences, das nossas ações e daquilo que construímos, o reconhecimento das novas gerações nas tradições de um povo, torna-se o impulso na preservação do patrimônio e da memória.

É através da memória que vivemos na transição constante das formas culturais determinadas pelos nossos antepassados, pela nossa sociedade, pela cultura do nosso povo. Contudo, a cultura pode ser manifestada pelas práticas sociais, à exemplo das construções arquitetônicas e das formas de 
empoderamento introduzidas por elementos paisagísticos, à citar os elementos decorativos nas platibandas e os assoalhos nos sobrados.

\section{Referências}

ABREU, João Capistrano de. Capítulos de História Colonial. Belo Horizonte: Itatiaia, 1988.

BRITO, Maria Creuza de Sá y. Petrolina, origem, fatos, vida, uma história. Impressora Tribuna do Sertão. 1995.

DINIZ, Nathalia Maria Montenegro. Um sertão entre tantos outros: fazendas de gado nas Ribeiras do Norte. Tese de doutorado. São Paulo: 2013.

DUARTE, Jorge de Souza. Juazeiro nos caminhos da história. Juazeiro: Impressora Rocha Ltda. 1985.

GURAN, Milton. Considerações sobre a constituição e a utilização de um corpus fotográfico na pesquisa antropológica. Texto apresentado ao Programa de Pós-Graduação em Antropologia Social da Faculdade de Filosofia Letras e Ciências Humanas da USP Universidade de São Paulo como parte integrante do relatório final de pós-doutorado (20042005). Consultado a 21.02.2016.

HALBWACHS, Maurice. A memória coletiva. São Paulo: Vértice, 1990.

LAKATOS, Eva e Marconi, Marina. Metodologia do Trabalho Científico. SP: Atlas, 1992.

LOPES, Sérgio Marcelino da Motta. Juazeiro: entre o rio e a história: delimitação, inventariação e requalificação de áreas de interesse histórico-arquitetônico em Juazeiro da Bahia. Trabalho de Conclusão de Curso de Arquitetura e Urbanismo, da Universidade Federal do Ceará, Outubro de 1999.

NORA, Pierre. Entre história e memória: a problemática dos lugares. Revista Projeto História. São Paulo 1993, p.21-22

POLLACK, Michael. Memória, esquecimento, silêncio. Estudos Históricos, Rio de Janeiro, vol.2, no $3,1989$.

REIS FILHO, Nestor Goulart. Quadro da Arquitetura no Brasil. São Paulo: Editora Perspectiva, 1978.

RICHARDSON, R. J. Pesquisa Social: métodos e técnicas. 3 ed. São Paulo: Atlas, 2012.

RUSKIN, John. Art and Illusion. New York, 1960.

\section{Fontes orais}

Maria Isabel Figueiredo, historiadora, memorialista, professora. Entrevistada nos dias 22 de maio de 2010 e 07 de junho de 2010 na sua residência no Condomínio Country Club. 
Stelitta Santana, entrevistada no dia 05 de agosto de 2010 na residência Rua Conselheiro João Alfredo, 2009.

Nei Barbosa, entrevistada no dia 19 de setembro de 2010 na residência a Rua Conselheiro João Alfredo, 2007.

Celita Ribeiro, entrevistada na Igreja Nossa Senhora Rainha dos Anjos em Petrolina/PE no dia 26 de outubro de 2011.

\section{Acervo}

Projeto de pesquisa e extensão O Arquivo de Maria Franca Pires: Memória e História Cultural em Pesquisa na região de Juazeiro-BA, coordenado pela professora Odomaria Bandeira Macedo, DCH III - UNEB. 